\title{
Atypical progression of visual loss in a patient with primary open-angle glaucoma
}

\author{
Progressão atípica de perda visual em paciente \\ com glaucoma primário de ângulo aberto
}

Marcelo Mendes Lavezzoํ, Roberto Battistella², Maria Kiyoko Oyamada²

\begin{abstract}
Dolichoectasia of the internal carotid artery (ICA) is a rare condition that may be associated with neuro-ophthalmic manifestations, such as loss of visual acuity and visual field resulting from compression of the optic nerve $(\mathrm{ON})$. The aim is to report a 67-year-old male patient with primary open-angle glaucoma (POAG) with atypical evolution, asymmetry of cupping and increased pallor of the rim of the left ON, due to compressive optic neuropathy by the dolichoectatic segment. The diagnosis was based on clinical history, appearance of the $\mathrm{ON}$ and neuroimaging.

Keywords: Optic nerve diseases; Vascular diseases; Glaucoma, open-angle; Magnetic resonance angiography; Case reports
\end{abstract}

\section{RESUMO}

A dolicoectasia da artéria carótida interna (ACI) é uma condição rara que pode ser acompanhada de manifestações neuro-oftalmológicas, como perda da acuidade e alteração do campo visual decorrente da compressão do nervo óptico (NO). O objetivo é relatar um caso de paciente do sexo masculino, 67 anos, portador de glaucoma primário de ângulo aberto (GPAA) com evolução atípica, assimetria de escavação, palidez da rima do NO à esquerda, devido à neuropatia óptica compressiva à esquerda, por segmento dolicoectásico da ACI. O diagnóstico foi baseado na história clínica, aspecto do $\mathrm{NO}$ e exames de neuro-imagem.

Descritores: Doenças do nervo óptico; Doenças vasculares; Glaucoma ângulo aberto; Angiografia por ressonância magnética; Relatos de casos

\footnotetext{
'Eye Clinic, University Hospital of the São Paulo University (USP), São Paulo/SP, Brazil.

${ }^{2}$ Neuro-ophthalmology Unit, Eye Clinic, University Hospital of the São Paulo University (USP), São Paulo/SP, Brazil.

Study conducted at the Eye Clinic of the University Hospital of the São Paulo University (USP), São Paulo/SP, Brazil.
}

The authors declare no conflicts of interest

Received for publication: 13/2/2012 - Accepted for publication: 4/11/2012 


\section{INTRODUCTION}

D olichoectasia of intracerebral vessels is a rare condi tion affecting the large arteries of the skull base, which suffer elongation and distension. The vertebrobasilar system is more frequently affected than the internal carotid arteries (ICAs). Neurological deficit can occur secondary to local embolism, thrombotic occlusion, compression, or rupture. Neuroophthalmic manifestations are related to compression of adjacent structures and include cranial nerve palsies, optic neuropathy, chiasmal syndromes, nystagmus, hemifacial spasm, and visual loss due to compression of the anterior optic pathways by dolichoectatic vessels ${ }^{(1)}$.

The aim of this paper is to report the case of a patient with primary open angle glaucoma (POAG) with asymmetric cupping, visual acuity, and visual field loss, more severe on the left side, with pallor of the ipsilateral optic nerve (ON) rim, in the presence of a dolichoectatic ICA compressing the left intracranial ON.

\section{Case report}

White, 67-year-old male patient complaining of insidious and progressive loss of visual acuity in both eyes (BE) starting 18 months ago, more severe on the left eye (LE). There was no pain or trauma. The patient had a history of diabetes mellitus, high blood pressure, severe chronic obstructive pulmonary dis-

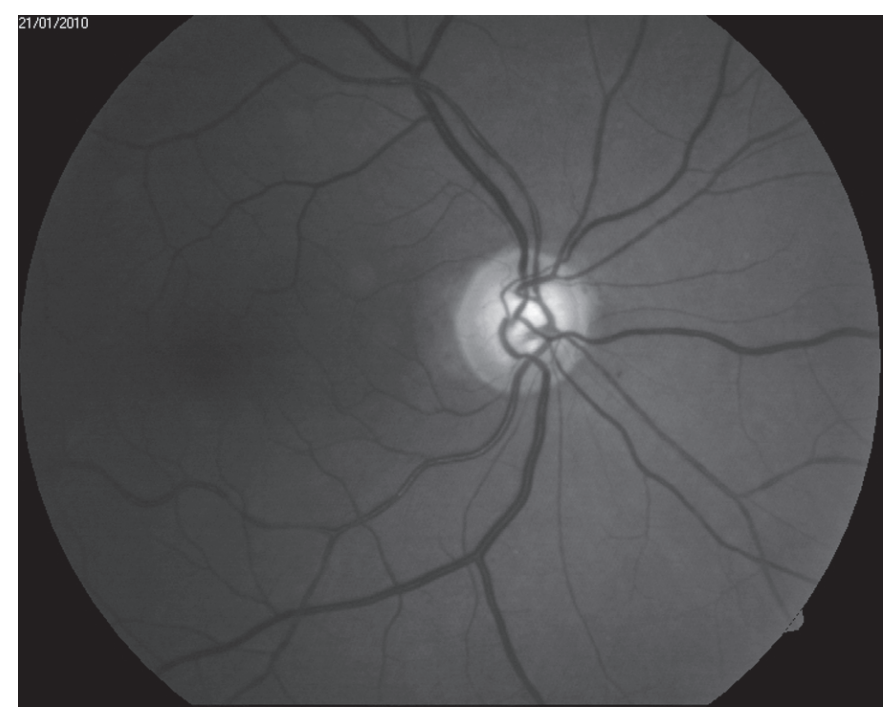

ease, and smoking.

Upon examination, he had a corrected visual acuity of 20/ 20 in the right eye (RE) and counting fingers from a distance of 4 metres in the LE. A decreased pupillary photomotor reflex and a relative afferent pupillary defect (RAPD) 3+/4+ were observed in the LE. Biomicroscopy showed a clear cornea, a deep anterior chamber without reaction, a trophic iris, and incipient nuclear cataract in BE. Intraocular pressure (IOP) was $35 \mathrm{mmHg}$ in the RE and $36 \mathrm{mmHg}$ in the LE. The patient had an open anterior chamber angle at 360 degrees and a visible scleral spur in BE. Ophthalmoscopy showed an ON rim of normal colour and cupping of $0.6 \times 0.7$ in the RE and a pale ON rim with cupping of $0.8 \times 0.9$ in the LE (Figure 1).

24:2 white-white automated perimetry (Humphrey Systems, San Leandro, California) showed an inferior arcuate defect in the RE and diffuse reduction of sensitivity in the LE (Figure 2). These findings were confirmed in at least three visual field tests.

The asymmetric progression with indolent visual loss, ON pallor, RAPD in the LE, and diffuse central visual field defect led to the hypothesis of a left pre-chiasmal compressive optic neuropathy. Thus, neuro-imaging tests (magnetic resonance imaging [MRI] and magnetic resonance angiography) were done, showing a dolichoectatic left ICA compressing the ipsilateral ON and pushing the left part of the optic chiasm upward (Figure 3).

Given the high IOP values, we opted for medical treatment with hypotensive eye drops $(0.03 \%$ bimatoprost, $0.2 \%$

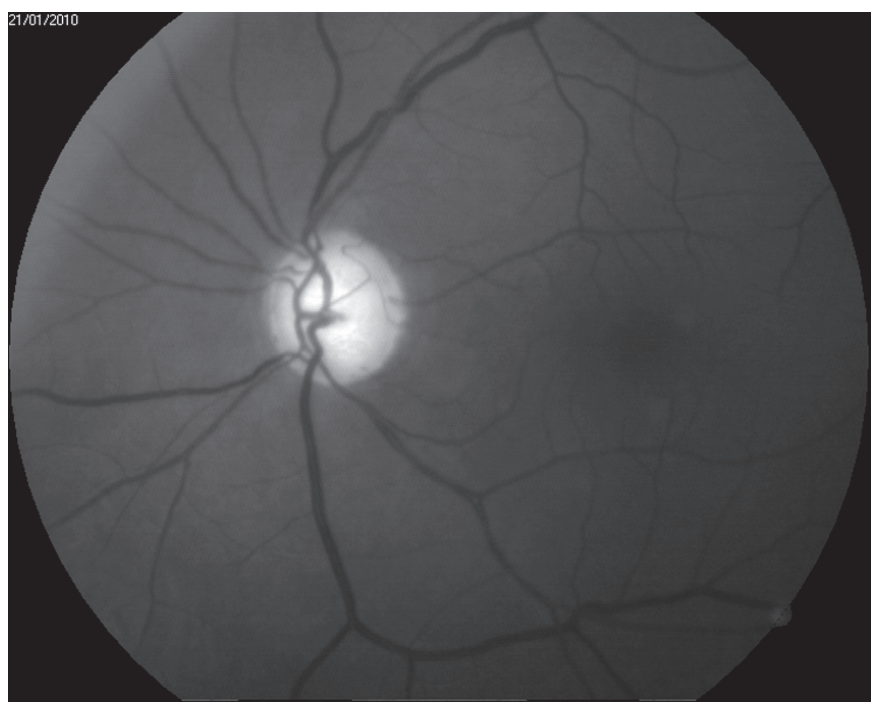

Figure 1. Fundus images showing a normal optic disc with cupping of 0.6 x 0.7 in the right eye and a pale optic disc with cupping of $0.8 \times 0.9$ in the left eye
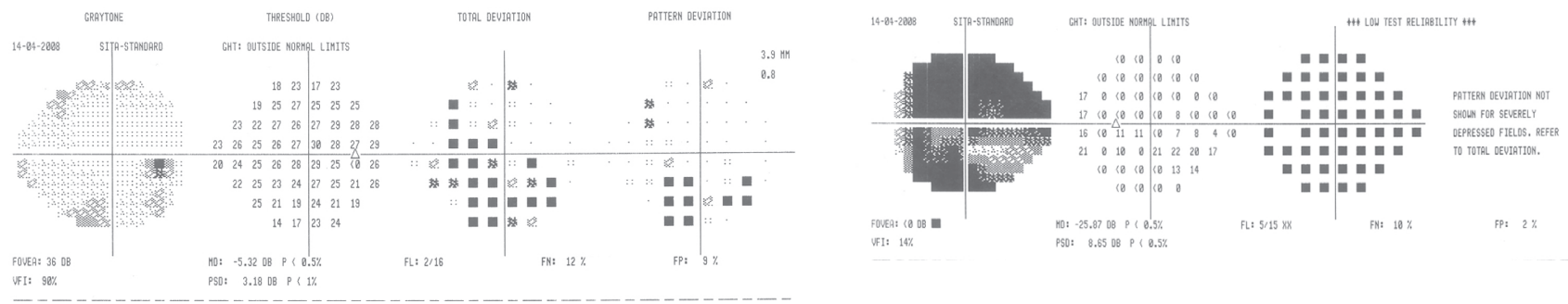

Figure 2. Automated perimetry (24:2, white-white) showing inferior arcuate defect in the right eye and diffuse reduction of sensitivity in the left eye. The findings in the left eye are compatible the severe cupping and optic disc pallor observed in retinography 

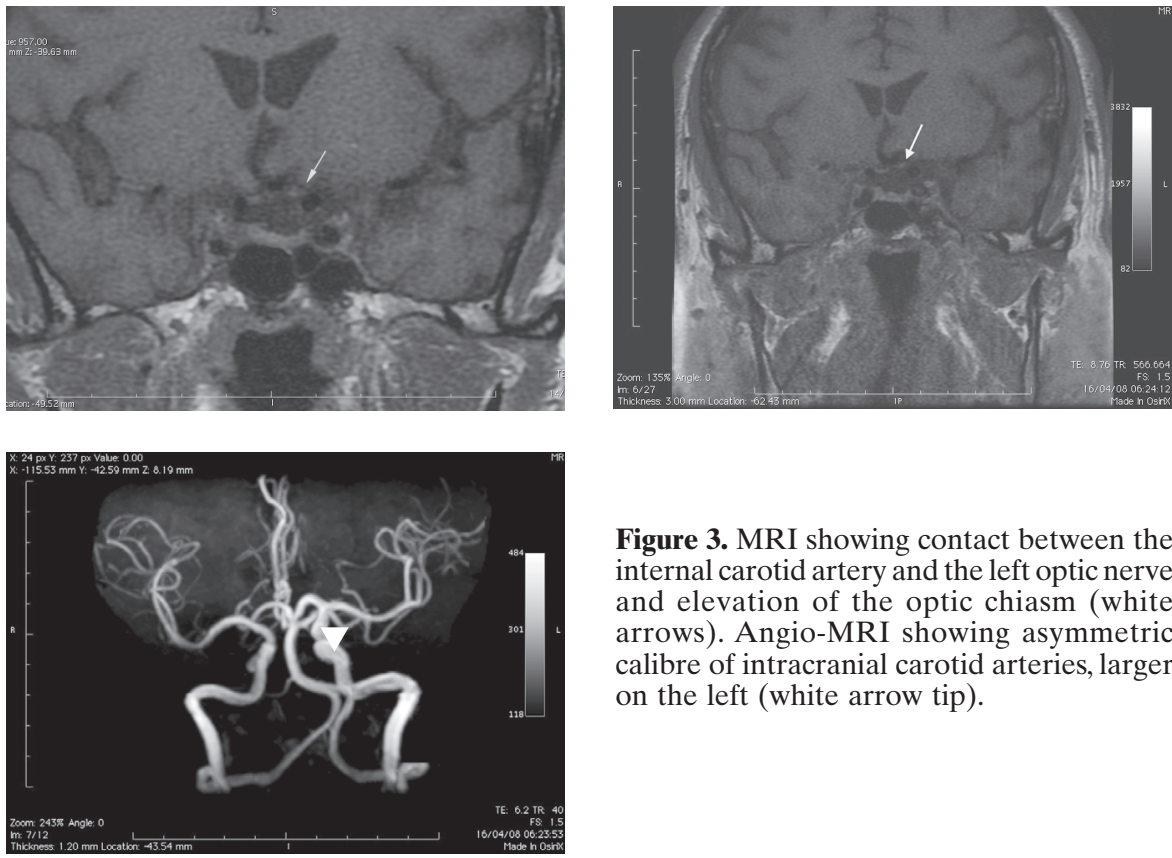

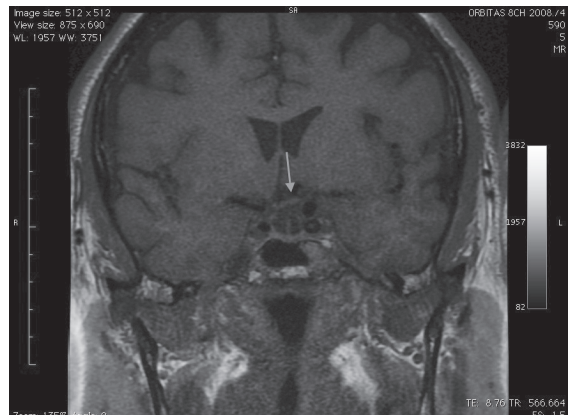

Figure 3. MRI showing contact between the internal carotid artery and the left optic nerve and elevation of the optic chiasm (white arrows). Angio-MRI showing asymmetric calibre of intracranial carotid arteries, larger on the left (white arrow tip).

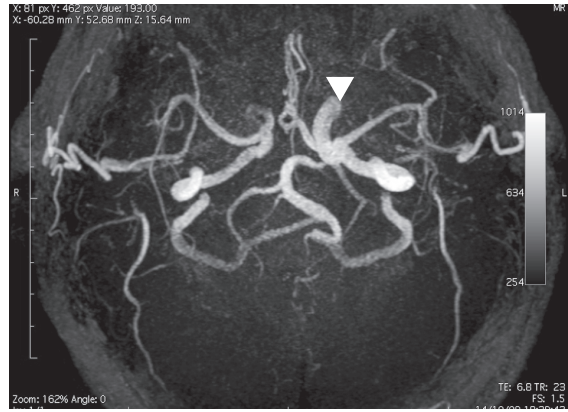

brimonidine tartrate, and $2 \%$ dorzolamide hydrochloride). The IOP was reduced $(12 / 14 \mathrm{mmHg})$ without progression of visual field defects in the RE. In the LE, no progression of the visual field defect was observed during a three-year follow-up period. As for the left optic pathway compression, after weighting the risks and benefits we opted for medical management.

\section{Discussion}

Dolichoectasia is a condition characterised by thinning of arterial walls, with substitution of elastic and reticular fibres by fibrous tissue. This results in increased length, tortuosity, and irregularity of the lumen. The most affected intracranial arteries are the internal carotid, vertebral, and basilar arteries ${ }^{(2)}$.

Although the normal limits for the position and diameter of the basilar artery have been well defined, the definition of a dolichoectatic ICA remains subjective. It is worth noting that the normal anatomical variability in the relationship between the ICA and the ON may predispose some patients to symptomatic compression ${ }^{(3)}$.

Glaucoma involves a characteristic loss of the superior or inferior arcuate retinal nerve fibres, but the papillo-macular bundle tends to be spared during the early stages of the condition, as seen in the RE of the case presented here. In compressive optic neuropathies, however, there is visual loss with an abnormal pupillary reflex and central or cecocentral visual field defects, and dolichoectasia of the ICA can be shown to be one of the causes of the neuropathy ${ }^{(2)}$.

Although POAG is a bilateral disease, it usually manifests asymmetrically, and there may be asymmetric cupping and visual field defects between the two eyes ${ }^{(2)}$. In the present case, there were significant differences between the two eyes (worse on the left) along with other findings (e.g., relative afferent defect and rapid progression of asymmetric glaucomatous disease) that raised the suspicion of an associated neuro-ophthalmic disease. For these reasons, neuro-imaging tests were done to clarify the diagnosis.
Dolichoectasia of the ICA can mimic normal tension glaucoma (NTG), as ON compression or insufficient vascular supply can cause ipsilateral visual field loss and increased cupping. Radiological studies have shown manifestations such as calcification, dilation, and ectasia of the intracavernous carotid arteries adjacent to the intracranial opening of the optic canal in patients with NTG. It is unclear whether there is a correlation between ON cupping asymmetry and the severity of carotid disease. The gradual widening of the ICA lumen (e.g., due to aging and high blood pressure) can result in compression of the adjacent $\mathrm{ON}$ in predisposed individuals $^{(2)}$.

Chronic compression of the ON can also compromise regional perfusion, producing ischemia in addition to the compressive damage to the nerve fibres. Moreover, long-term compression of the intracranial $\mathrm{ON}$ can produce a pattern of visual field loss in nerve fibre bundles and ON cupping, consistent with glaucoma $^{(3)}$. In the case presented here, in addition to the glaucomatous damage in $\mathrm{BE}$, the effects of $\mathrm{ON}$ compression by the left dolichoectatic ICA should be considered, resulting in asymmetric cupping and a pale $\mathrm{ON}$ rim.

A study using MRI showed that anatomical compression of the intracranial ON by the supra-clinoid ICA occurs relatively frequently in asymptomatic patients. Thus, identifying this relationship, by itself, may not be clinically relevant. Still, there are reports of patients with occult or progressive optic neuropathy in which no other plausible mechanism of ON damage exists ${ }^{(3)}$.

Some authors suggest that the most reliable specific signs of non-glaucomatous damage associated with compressive lesions are age under 50 years, ON pallor with increased cupping, and visual field defects respecting the vertical meridian. In such cases, neuro-imaging tests would be indicated ${ }^{(4)}$.

$\mathrm{ON}$ decompression often does not result in significant visual recovery and is associated with a higher morbidity and mortality ${ }^{(3)}$. Therefore, in the case presented here we opted for medical management.

After reviewing the literature on the subject, the authors found no similar cases in the Brazilian literature.

In conclusion, when atypical signs are found in glaucoma, 
the ophthalmologist should be alert to the possibility of an associated compressive lesion. For an accurate diagnosis it is necessary to evaluate not only the appearance of the cupping, but also the residual neural rim, the pattern of retinal nerve fibre loss, and the visual field defect, as well as the pupillary reflex and colour vision. Once there is a suspicion of optic nerve or chiasm compression, neuro-imaging tests such as MRI and angio-MRI should be done.

\section{References}

1. Purvin V, Kawasaki A, Zeldes S. Dolichoectatic arterial compression of the anterior visual pathways: neuro-ophthalmic features and clinical course. J Neurol Neurosurg Psychiatry. 2004;75(1):27-32.

2. Ellis MF, Scott M, Erwin G. Carotid artery ectasia coexistent with primary open angle glaucoma. Clin Experiment Ophthalmol. 2001;29(1):44-6.
3. Jacobson DM. Symptomatic compression of the optic nerve by the carotid artery: clinical profile of 18 patients with 24 affected eyes identified by magnetic resonance imaging. Ophthalmology. 1999;106(10):1994-2004. Comment in Freeman JY, Newman NJ. Carotid artery compression of the optic nerve. Ophthalmology. 2000;107(10):1798-9.

4. Greenfield DS, Siatkowski RM, Glaser JS, Schatz NJ, Parrish RK 2nd. The cupped disc. Who needs neuroimaging? Ophthalmology. 1998;105(10):1866-74. Comment in Lee AG. Differentiating glaucomatous from nonglaucomatous optic atrophy. Ophthalmology. 1999;106(5):855.

\section{Corresponding author:}

Marcelo Mendes Lavezzo

Rua Capote Valente, 136 - apto. 54

05409-000 Jardim América - São Paulo (SP), Brazil.

Tel: +55113062 4968/+551130696289

E-mail:mmlavezzo@gmail.com 